\title{
O professor formador como objeto de pesquisa e o início das pesquisas no Brasil sobre formadores de professores de línguas estrangeiras ${ }^{1}$
}

\section{The University Teacher Educator as Research object and the Initial Research about Foreign Language Teacher Educators in Brazil}

Regina Célia Halu*

Universidade Federal do Paraná (UFPR)

Curitiba - Paraná / Brasil

\begin{abstract}
RESUMO: Este trabalho visa situar o surgimento do professor formador universitário como objeto de pesquisas acadêmicas, considerando o contexto brasileiro e com foco mais específico nos formadores de professores de línguas estrangeiras. Pressões globais e nacionais teriam trazido à tona a necessidade de contemplar uma formação integral do professor do ensino superior, o que pode ser evidenciado por programas do governo, por iniciativas de instituiçóes de ensino superior e pelo próprio desenvolvimento de pesquisas sobre o professor formador em várias áreas, incluindo a de línguas estrangeiras. Um levantamento bibliográfico dessas pesquisas no Brasil na primeira década do século XXI, a partir dos principais bancos nacionais de teses e dissertaçōes, mostra a gradual abertura dos programas de pós-graduação na área de Letras e Linguística Aplicada para a pesquisa sobre formação de professores e formadores e o início do tratamento de questôes e contextos específicos da formação profissional de professores formadores universitários atuando na área de línguas estrangeiras.
\end{abstract}

PALAVRAS-CHAVE: professor formador universitário, formação de professores de línguas estrangeiras, levantamento bibliográfico.

\footnotetext{
*reghalu@gmail.com

${ }^{1}$ Essa pesquisa bibliográfica foi iniciada como parte da minha tese de doutorado intitulada Formação de Formadoras de Professoras de Inglês em Contexto de Formação Continuada (NAP-UFPR), sob orientação da professora Dra. Clarissa Menezes Jordão, no Programa de Pós-Graduação em Letras da Universidade Federal do Paraná (UFPR), com bolsa da CAPES.
} 
ABSTRACT: This paper aims to situate the emergence of the university teacher educator as an object of academic research, considering the Brazilian context and focusing more specifically on the foreign language teacher educator. Global and national pressures have brought to surface the need to consider the processes of education for the higher education professor, which has been evidenced by governmental programs, initiatives in higher education institutions, and the development of a body of research about university teacher educators in several areas, including the area of foreign language teaching. A bibliographic search of the academic research in Brazil during the first decade of the 21st century, based on the main national thesis and dissertation databases, shows the gradual increase of research about teacher and teacher educator education and the initial interest in specific questions about and contexts for the professional education of university foreign language teacher educators by graduate programs in Letters and Applied Linguistics. KEYWORDS: university teacher educator, foreign language teacher education, bibliographic search.

\section{Introdução}

Embora seja claro o papel pilar dos formadores de professores na construção de uma base sólida para a educação brasileira (MIZUKAMI, 2005), desde a formação inicial e continuada dos professores até o planejamento de políticas e reformas educacionais, eles próprios se encontram em fase de construção inicial enquanto objeto de preocupação de pesquisas no universo acadêmico. Levantamentos sobre o estado da arte da pesquisa sobre formação de professores em nosso país (ANDRÉ et al., 1999; BRZEZINSKI; GARRIDO, 2001) mostram que até o final da década de 1990 o formador de professores e os processos de sua formação praticamente não eram contemplados como objetos de reflexão. Situação semelhante foi observada nos países da América Latina (MESSINA, 1999; VAILLANT, 2003), enquanto nos Estados Unidos as pesquisas nessa área começaram a tomar corpo por volta do início da década de 1990 (COCHRAM-SMITH, 2003, p. 6-7). Em outro levantamento, Andrade (2007), comparando as pesquisas brasileiras nos anos 1990 e a partir de 2000, inclui a formação de professores do ensino superior na lista dos temas que emergiram no início desse milênio.

$\mathrm{Na}$ área de línguas estrangeiras o surgimento do professor formador como objeto de pesquisa é ainda mais recente (GRAY, 2001; ALVES, 2005; DUARTE, 2006). No Brasil, uma parte das pesquisas com esse foco tem vindo de uma comunidade de formadores de professores de inglês que se reuniu em torno dos ENFOPLIs - Encontros de Formadores de Professores de Língua Inglesa, a partir de 2002, no estado do Paraná (CRISTÓVÃO; 
GIMENEZ, 2005; ORTENZI et al., 2005; PERIN, 2006 e 2009; GIMENEZ; CRISTÓVÃO, 2007; RAMOS; CAMARGO, 2007; CORREA; CALVO; GIMENEZ, 2010). Ao analisar os trabalhos apresentados no I CLAFPL - Congresso Latino Americano de Formação de Professores de Línguas, realizado em 2006, Ortenzi (2007) observou o surgimento do tema "formação dos formadores de professores", com trabalhos abordando suas concepçôes e práticas, tema que raramente aparecia no levantamento anterior dos estudos de formação de professores de línguas no Brasil realizado por Gil (2005). É, portanto, recente a concretização da figura do formador nas pesquisas sobre formação de professores.

O início do desenvolvimento dessas pesquisas pode ser interpretado como resultado de um efeito dominó ao redor do mundo: as fortes mudanças sociais, políticas, econômicas e tecnológicas que caracterizaram a virada do milênio criaram novas demandas para o indivíduo (cidadão/trabalhador), o qual espera, ao menos em parte, obter uma preparação adequada na escola, o que exige um novo perfil de professor, na formação do qual o formador é peça fundamental. Como coloca Cochran-Smith (2003, p. 5), é o formador universitário que forma os professores dos quais se espera que sejam capazes de ensinar dentro de novos padrões curriculares no ensino básico, letrar os alunos para o mundo digital, integrar o uso de tecnologia em todas as disciplinas, atender as necessidades de uma população estudantil cada vez mais diversa e assegurar que seus alunos tenham bom desempenho nos exames nacionais (como o ENEM, no contexto brasileiro). Do formador, docente universitário, se espera também que se posicione quanto às discussōes sobre novas alternativas de certificação profissional, construa parcerias com as escolas e a comunidade, capte recursos para financiamentos de pesquisa, participe da administração universitária, cumpra as regulamentaçôes educacionais, desenvolva currículos, se envolva nos programas de pós-graduação (ANASTASIOU; PIMENTA, 2002; COCHRAN-SMITH, 2003).

Ocorre que essas novas demandas sobre o formador não são acompanhadas de uma atenção para o seu próprio preparo, por meio, por exemplo, de uma discussão sobre contextos e currículos adequados para sua formação ou de políticas de apoio para seu desenvolvimento contínuo. Como observa Cochran-Smith (2003, p. 6), essa percepção de que os formadores de professores haviam sido negligenciados por muito tempo não se deu apenas nos Estados Unidos, mas surgiu a partir de meados dos anos 1990 também em países como a Holanda, Noruega, Israel e Austrália. 
No Brasil, julgo importante observar a pressão criada pelo desenvolvimento dos programas de avaliação do ensino superior a partir dos anos 1990 (como o PAIUB, o Exame Nacional de Cursos² e, a partir de 2004, as avaliaçóes do $\mathrm{SINAES}^{3}$ ). Ainda que tais programas avaliativos tenham tido seus modelos criticados (CUNHA, 2004), é possível considerar que ao menos eles contribuíram para chamar a atenção sobre a questão da qualificação acadêmica e didática de seus professores, o que acabou por resultar em algumas medidas oficiais e iniciativas em várias instituições de ensino superior (IES) voltadas para a formação para a docência no nível superior, assim como incentivar o desenvolvimento das pesquisas sobre o professor e sua formação para a docência (ALVES, 2005, p. 55). Entre as iniciativas de maior proeminência desenvolvidas por IES na área de formação para a docência no nível superior, devem ser mencionados o Programa de Estágio e Capacitação Docente (PECD) da Universidade de Campinas (UNICAMP) e o Programa de Aperfeiçoamento Pedagógico da Universidade de São Paulo (PAE/USP). Outro exemplo de iniciativa local, alinhado com uma política avaliativa formal e uma abordagem generalista, foi a oferta em 2009 pela UFPR de um curso de curta duração $(90 \mathrm{~h})$ de Metodologia do Ensino Superior na modalidade a distância (com base na plataforma Moodle), obrigatório para todos os

\footnotetext{
${ }^{2}$ Durante o governo de Itamar Franco (1992-1994), uma comissão de especialistas, formada por iniciativa da ANDIFES (Associação Nacional dos Dirigentes das Instituiçōes Federais de Ensino Superior) criou o Projeto de Avaliação Institucional, o qual foi adotado pelo MEC e tornou-se em 1993 o Programa de Avaliação Institucional das Universidades Brasileiras (PAIUB). Contando com a adesão voluntária das universidades, objetivava uma transformação universitária. Ele foi depois substituído pelo Exame Nacional de Cursos (Provão), que vigorou entre 1996 e 2003. Junto com ele, outros instrumentos de avaliação foram implementados durante os governos de Fernando Henrique Cardoso, tal como a Avaliação das Condiçôes de Oferta (ACO), que pretendia analisar a organização didáticopedagógica, o corpo docente e as instalações. Diferentemente do PAIUB, tratou-se nesse período de se tentar impor uma cultura avaliativa de fora para dentro, baseada no estímulo à competitividade. A comunidade acadêmica passava de sujeito avaliador de sua prática e seus conhecimentos para a posição de objeto avaliado (BRASIL SINAES, 2007, p. 30).

${ }^{3}$ Em 2004, foi instituído o SINAES - Sistema Nacional de Avaliação da Educação Superior, o qual criou o Exame Nacional de Estudantes (ENADE), para avaliação do desempenho dos alunos, complementado com a avaliação de cursos e instituições.
} 
professores ingressantes naquele ano. ${ }^{4}$ Entre as medidas oficiais, encontra-se a exigência que passou a ser feita pela CAPES (Ofício Circular n ${ }^{\circ}$.028/99) de realização de estágio de docência na graduação para seus bolsistas de pósgraduação. Outra medida foi a regulamentação feita pela CAPES em 2004 do Programa de Apoio a Projetos Institucionais com a Participação de RecémDoutores - PRODOC. Na justificativa do programa, é reconhecido haver uma lacuna na formação de mestres e doutores que, recém-titulados, venham a atuar imediatamente em programas de pós-graduação (Portaria nº. 087, de 09 de novembro de 2004). Em 2006, a Secretaria de Educação Superior do Ministério da Educação criou o Programa de Consolidação das Licenciaturas - PRODOCÊNCIA, o qual tem, entre outros, o objetivo de "ampliar e dinamizar as ações voltadas à formação de professores, priorizando a formação inicial desenvolvida nos cursos de licenciaturas das Instituiçôes Federais e Estaduais de Ensino Superior" (BRASIL - MEC, 2007).

Além disso, nos debates em torno da centralidade da educação básica que caracterizaram a década de 1990 em nosso país, nas políticas e programas governamentais para a formação continuada, implementadas com o financiamento de agências internacionais, o professor das IES não vinha sendo apontado como aquele a exercer o papel de formador, sendo preterido por técnicos ou especialistas indicados pela agência financiadora, ou, quando participando dos programas, exercendo apenas o papel de provedor de serviços, sem participação na gestão de tais programas.

No meu entendimento, todo esse contexto gerou se não um descontentamento, ao menos um grande desconforto entre os professores formadores universitários. Isso pode ser tido um efeito positivo ao provocar um maior desenvolvimento de discussões, estudos e pesquisas sobre os papéis da universidade, ${ }^{5}$ com um foco mais específico no papel do formador universitário na formação inicial e continuada de professores da educação básica e também na formação dos próprios professores formadores universitários.

${ }^{4} \mathrm{O}$ caráter obrigatório e avaliativo do curso se respaldava em uma resolução da Universidade (02/00 - COPLAD), que dispunha sobre a avaliação de desempenho dos docentes em estágio obrigatório e que incluía como papel das Comissóes Avaliadoras a consideração na avaliação do aproveitamento apresentado pelos professores avaliados no programa de formação continuada.

${ }^{5}$ Isso pode ser observado nos últimos anos por meio da crescente realização de eventos e abertura de grupos com essa temática específica nas associaçóes e entidades de educadores (ANPED, ANPOLL, ENDIPE, ENFOPLI, entre outros). 


\section{As pesquisas sobre formadores de professores}

No Brasil, a maioria das pesquisas acadêmicas que tratam do professor formador universitário e sua formação são desenvolvidas em programas de pósgraduação da área de Educação (ANTUNES, 2002; ALVES, 2005, p. 51, PIMENTA; ANASTASIOU, 2003, p. 40). Nesses trabalhos, embora as pesquisas de campo por vezes enfoquem professores atuando em cursos específicos ou em disciplinas ou áreas específicas mais explicitamente relacionadas à formação pedagógica dentro de cursos de licenciatura (Prática de Ensino, Supervisão de Estágio, Metodologia de Ensino), as discussões tendem a tratar genericamente da figura do professor formador e suas questóes. Ao abordarem, por exemplo, os conflitos entre formação pedagógica e formação para a pesquisa, as quais têm se dado de forma dissociada e hierarquizada (com a preparação para e o exercício da docência em um nível inferior), tendem a pensar na universidade como um todo e a contemplar questôes de formação pedagógica, identificada como deficitária, tendo como referente o professor universitário em geral. Nessas pesquisas é desenvolvida uma discussão sobre como fortalecer os três eixos principais da formação de um professor universitário - o aprendizado de práticas e concepçóes pedagógicas, o aprofundamento na disciplina lecionada e o aprendizado de práticas e concepções de pesquisa, tentando apresentar considerações válidas para docência e pesquisa em qualquer disciplina ou área do conhecimento e para a atuação na formação em nível universitário de qualquer profissional.

Nesses estudos e debates foram feitas algumas constatações, críticas e sugestôes importantes quanto às questóes amplas sobre o professor universitário e sua formação. Assim, Cunha (2004), ao chamar atenção para o fato de que no Brasil (e em outros países igualmente) "o grau superior é o único para o qual não há previsão legal de formação específica para o magistério", resume parte do quadro atual de formação de professores universitários. As políticas do ensino superior nas últimas duas décadas, embora tenham tido, entre seus objetivos, o de assegurar a expansão e melhoria dos sistemas de formação do professor da educação básica e do próprio professor universitário, encontram-se limitadas por uma cultura que enfatiza a importância da pesquisa e desprestigia o ensino. Resulta daí a pouca atenção dada à formação pedagógica de seus próprios professores, a qual, por sua vez, acaba por ser concebida também como conhecimento independente ou desconectada dos conhecimentos específicos da disciplina do professor. Apesar da constatação dessa negligência, Alves (2005, p. 57) considera que aos poucos 
se forma uma consciência de que "a docência no ensino superior exige capacitação, a qual vai além da posse do diploma de Bacharel, Mestre ou Doutor, pois para ser professor há necessidade de competências pedagógicas”. A existência de esforços em contemplar uma formação integral do professor do ensino superior estaria evidenciada em programas do governo, iniciativas de IES e pelo desenvolvimento das pesquisas na área.

O desafio de realizar a junção das atividades de ensino, pesquisa e extensão no nível superior tem levado à discussão sobre os contextos adequados para a promoção da formação do docente universitário. As propostas para uma formação inicial ${ }^{6}$ obrigatória ou padronizada, por meio, por exemplo, de cursos de especialização ou de disciplinas e estágios na pós-graduação levanta polêmicas (DIAS SOBRINHO, 1998). Carvalho et. al. (2001, p. 181) observam que, apesar de ter sido atribuído historicamente à pós-graduação o papel de suprir uma formação inicial do docente de nível superior, esta não tem correspondido "[nem às] demandas de formação e nem para instaurar uma discussão sobre o trabalho pedagógico no interior das universidades". Masetto (2003, p. 184) se coloca a favor de uma abertura real dos programas de pósgraduação para oferecer essa formação pedagógica, seja por meio de disciplinas optativas ou por seminários e oficinas (os quais poderiam ser ofertados para os docentes já atuando na instituição), ou ainda pelo desenvolvimento de pesquisas sobre o ensino superior nas diversas áreas. Mas também ele reconhece que os programas de pós-graduação cumprem seu papel na formação de pesquisadores, mas não garantem a formação de docentes. Acaba por ser consenso entre os pesquisadores que, sendo poucas as opções de formação inicial dirigidas a esse docente, é na prática que ocorre sua formação e que, portanto, ela depende em curto prazo principalmente de políticas e programas governamentais e/ou institucionais voltados para a formação em serviço (PIMENTA; ANASTASIOU, 2002, p. 108; PACHANE, 2003, p. 109110; MASSETO, 2003, p. 185; ALVES, 2005, p. 65).

Contemplando questões comuns relativas à formação docente de todo professor universitário, esses estudos já oferecem uma base de reflexões que podem permitir o tratamento de questôes específicas a cada contexto de

\footnotetext{
${ }^{6}$ Pachane (2003, p.107) conceitua formação inicial como "preparação formal numa instituição específica de formação de professores, na qual o futuro professor adquire conhecimentos pedagógicos e de disciplinas acadêmicas, assim como realiza as práticas de ensino, ou estágios".
} 
formação em que os professores atuam e a suas áreas de conhecimento. Um levantamento nos principais bancos nacionais de teses e dissertações mostra que esse caminho começa a ser explorado, principalmente em pesquisas voltadas para aquele professor do ensino superior que forma os professores da educação básica, ou seja, aqueles que atuam em cursos de Pedagogia e outras licenciaturas. Gomes (2006), realizando pesquisa de mestrado em Educação na PUC de Campinas, ao analisar as concepções de conhecimento pedagógico do docente formador de professores, optou por contrastar os discursos vindos de três áreas do conhecimento - exatas, biológicas e humanas, por ter como pressuposto que "o problema maior na Educação não é tão somente pedagógico, mas também de natureza epistemológica” e, assim, considerou "a construção do conhecimento como referência para a análise das falas do docente formador". A tese de doutorado em Educação apresentada por Rodrigues (2006) volta-se para o tratamento das questões específicas de professores e formadores de professores na área de Física. Oliveira (2007), em seu trabalho de doutorado, analisa as relaçôes entre os conhecimentos específicos e pedagógicos e a prática de formadores de professores de Matemática. Quadros (2010) enfocou a formação e atuação de professores de Química na UFMG.

\section{Formadores de professores de línguas}

$\mathrm{Na}$ área de Letras, Alves (2005, p. 65) recupera as considerações sobre formação, conhecimento e poder feitas por Leite e Cunha quase uma década antes de sua pesquisa:

[...] como alertam Leite e Cunha as decisões pedagógicas na universidade resultam de questôes epistemológicas e políticas, próprias das diversas áreas de conhecimento, presentes no contexto universitário. Portanto, "não é possível falar genericamente em uma pedagogia universitária, como se todos os cursos de uma universidade fossem regidos pela mesma lógica”. (LEITE; CUNHA, 1996, p. 85).

Apesar disso, sua pesquisa de mestrado envolvendo professores da Faculdade de Letras da UFMG, desenvolvida no programa de pós-graduação em Educação da PUC-MG, vai tratar genericamente de questões como a necessidade de formação pedagógica para o docente do ensino superior e o papel da pós-graduação para a formação para a docência, sem questionar, por exemplo, o fato de sua própria pesquisa ser realizada fora de um programa de 
pós-graduação em Letras ou as relações específicas entre concepções de língua, pesquisa em linguística e literatura e formação de professores e formadores nessa área específica. Ocorre também que, mesmo que uma pesquisa se realize num programa de pós-graduação em Letras, o pesquisador pode escolher não priorizar as relaçôes entre o contexto de atuação dos formadores, suas reflexões e práticas pedagógicas e as questôes e conhecimentos específicos de sua área de conhecimento. Freitas (2004, p.21), por exemplo, em sua pesquisa de doutorado envolvendo professoras de Prática de Ensino de língua inglesa, observa que "grande parte do conjunto de convicções das professoras formadoras se origina de suas experiências no campo de ensino de línguas, bem como no de formação de professores de língua estrangeira, ambos significativamente informados pelos estudos em Lingüística Aplicada", mas deixa explícito que seu enfoque prioriza uma discussão sobre ensino em time num nível mais abrangente da experiência docente.

Entretanto, aos poucos e principalmente à medida que os programas de pós-graduação em Letras e em Linguística Aplicada abrem espaço para a pesquisa sobre a formação de professores e formadores, questōes mais específicas à área de ensino de línguas estrangeiras começam a ser levantadas: o conhecimento teórico metodológico específico (aquisição e ensino de LE) que informa a prática do professor formador (CHIARELI, 2005; CLAUS, 2005; GONÇALVES, 2006), a interação entre formador e professor e a relação identitária com a língua e cultura alvo (ORTALE, 2003), a prática dos formadores como processo de aprendizagem e desenvolvimento profissional (ORTENZI, 2007). Nessas pesquisas, acompanha-se o professor formador em sua atuação em cursos de Letras, na formação inicial de professores de línguas. Nelas, a observação e a análise dos discursos e das práticas dos formadores nem sempre vão corroborar o pressuposto de uma formação em serviço que se dá por meio de reflexão crítica, questionando "não só [as] atividades de ensino, mas também [esse] próprio ensino em relação ao contexto social maior" (GIMENEZ et al., 2000). Chiareli (2005), observando professores de língua inglesa em cursos de licenciatura em Letras, considera que não foi possível perceber por parte dos formadores uma atitude de reflexão sobre suas próprias práticas (verificando-se, por exemplo, a cristalização de abordagens de ensino adotadas), concluindo que o exercício profissional por si só não garante o engajamento em um processo de formação continuada.

Porém, é possível observar que parte dessas pesquisas concentra-se na descrição e análise de práticas de formadores que se constituem em processos 
de sua própria aprendizagem. Freitas (2004, p. ii), como já citei, propôs analisar "como se configura a experiência de ensino em time e como as professorasformadoras [de inglês], isto é, as colegas de time, constroem significados de seus movimentos a partir da mesma”. Ortenzi (2007, p. 13) investigou e participou de uma iniciativa de produção coletiva de material pedagógico para a disciplina de Prática de Ensino de Inglês em um curso de Letras, considerando que uma análise desse processo traria "elementos para compreender de que forma se dá a aprendizagem e o desenvolvimento profissional no trabalho”. Já no final da década de 2000, duas pesquisas enfocam a formação de professores formadores de professores de inglês a partir de uma visão de aprendizagem social em comunidades. Perin (2009), em sua pesquisa de doutorado, se propôs a investigar o surgimento e o desenvolvimento do ENFOPLI (a série de Encontros de Formadores de Professores de Língua Inglesa), tratado como uma comunidade de prática. A própria pesquisadora coloca-se como "formadora em formação" ao analisar as práticas compartilhadas nesse "espaço não institucionalizado de formação profissional” (PERIN, 2009, p. 214-215). Minha própria pesquisa de doutorado (HALU, 2010) traz explicitamente o foco para o formador universitário de professores de línguas. A pesquisa buscou explorar questôes específicas da área de línguas para tratar da formação do professor formador imerso em práticas discursivas e não discursivas desenvolvidas e compartilhadas por uma comunidade de professoras formadoras na área de inglês ao longo de dois anos de trabalho de formação continuada em um núcleo de extensão universitária, o NAP-UFPR (Núcleo de Assessoria Pedagógica).

Dessa forma, inicia-se a construção de um corpo de pesquisas que delineia caminhos possíveis de formação do formador na área de línguas estrangeiras, sendo que as próprias pesquisas neles se inserem como práticas profissionais e de formação.

\section{Referências}

ALVES, M. S. A. Formação Pedagógica e seu Significado para os Docentes do Ensino Superior: um estudo com professores da Faculdade de Letras da UFMG. $133 \mathrm{f}$. Dissertação (Mestrado em Educação). Pontifícia Universidade Católica de Minas Gerais, Belo Horizonte, 2005.

ANASTASIOU, L. G. C.; PIMENTA, S. G. Docência no ensino superior. São Paulo: Cortez Editora, 2002. 
ANDRADE, R. R. M. Pesquisas sobre Formação de Professores: uma comparação entre os anos 90 e 2000. Anais da 30a Reunião Anual da ANPED, GT8-3165. Caxambu, 2007. Disponível em: <http://www.anped.org.br/ reunioes/30ra/trabalhos/GT08-3165-Int.pdf>. Acesso em: 22 abr. 2008.

ANDRÉ, M.; SIMŌES, R. H. S.; CARVALHO, J. M.; BRZEZINSKI, I. Estado da arte da formação de professores no Brasil. Educação e Sociedade, Campinas, v. 20, n. 68, p. 299-309, dez. 1999.

ANTUNES, M. N. V. A formação continuada do professor universitário de enfermagem: discutindo sua contribuição com as mudanças no ensino de enfermagem. Dissertação (Mestrado), Faculdade de Educação, Universidade Estadual de Campinas, Campinas, 2002.

BRASIL. Ministério da Educação. Edital n. $0^{\circ}$ 05/2007: Programa de Consolidação das Licenciaturas - PRODOCÊNCIA 2007. Disponível em: <http://portal.mec.gov.br/ arquivos/pdf/edital_prodocencia_05_2007.pdf>. Acesso em: 22 mar. 2008.

BRZEZINSKI, I.; GARRIDO, E. Análise dos trabalhos do GT Formação de Professores: o que revelam as pesquisas do período 1992-1998. Revista Brasileira de Educação, São Paulo, n. 18, p. 82-100, set.-dez. 2001.

CARVALHO, D. C.; SPONCHIADO, J. I.; SILVA, V. B. M. Investigando os saberes docentes na Universidade Federal de Santa Catarina. In: 24a. Reunião Anual da ANPED, 2001, Caxambu. Anais da 24a. Reunião Anual da ANPED. Rio de Janeiro: ANPED, 2001. p. 179-189.

CHIARELI, M. P. B. As abordagens de ensino de lingua estrangeira em cursos de Letras: uma visão do docente formador. 155 f. Dissertação (Mestrado em Educação) Faculdade de Educação, Pontifícia Universidade Católica, Campinas, 2005.

CLAUS, M. M. K. A formação da competência teórica do professor de língua estrangeira: o que revelam os estágios. $135 \mathrm{f}$. Dissertação (Mestrado em Letras). Instituto de Estudos da Linguagem da Universidade Estadual de Campinas (UNICAMP), Campinas, 2005.

CRISTOVÃO, V. L. L.; GIMENEZ, T. N. (Org.). ENFOPLI: construindo uma comunidade de formadores de professores de inglês. Londrina: Gráfica e Editora ArtGraf, 2005.

COCHRAN-SMITH, M. Learning and unlearning: the education of teacher educators. Teaching and Teacher Education International Journal of Scholarship and Studies, v. 19, p. 5-28, 2003.

CORREA, L. N.; CALVO, L. C. S.; GIMENEZ, T. Comunidades de prática na internet: um estudo com formadores de professores de inglês. In: I CIELLI - Colóquio Internacional de Estudos Linguísticos e Literários, 2010, Maringá. Anais... Maringá: UEM, 2010. 
CUNHA, L. A. Desenvolvimento desigual e combinado no ensino superior estado e mercado. Educação \& Sociedade, Campinas, v. 25, n. 88, p. 795-817, Especial - Out. 2004. Disponível em: <http://www.cedes.unicamp.br>. Acesso em: 14 out. 2007.

DIAS SOBRINHO, J. Pós-graduação, escola de formação para o magistério superior. In: SERBINO et. al. Formação de Professores. São Paulo: Editora da UNESP, 1998. p.139-148.

DUARTE, K. C. F. S. Formação de Professores de Lingua Estrangeira Moderna Espanhol: uma análise das concepções teóricas e metodológicas no ensino superior de Campo Grande - MS. 209f. Dissertação (Mestrado em Educação) Universidade Católica Dom Bosco, Campo Grande, 2006.

GIL, G. Mapeando os estudos de formação de professores de línguas no Brasil. In: FREIRE, M.; ABRAHÃO, M. H.; BARCELOS, A. M. (Org.). Lingüística Aplicada e contemporaneidade. Sâo Paulo: ALAB/Pontes, 2005. p. 173-182.

GIMENEZ, T.; CRISTÓVÃO, V. L. L. Formadores de professores de inglês como pesquisadores. In: GIMEZES, T. (Org.). Tecendo as Manhãs: pesquisa participativa e formação de professores de inglês. Londrina: UEL, 2007. p. 1-22.

GIMENEZ, T.; REIS, S.; ORTENZI, D. Fé cega e faca amolada: observações sobre imagens de professores de Prática de Ensino de Inglês. DELTA - Revista de Documentação de Estudos em Linguística Teórica e Aplicada, São Paulo, v. 16, n. 1, p. 129-138, 2000.

GOMES, Rita de Cássia Medeiros. Formação de Professores: um olhar ao discurso do docente formador. Revista E-Curriculum, São Paulo, v. 2, n. 3, dez. 2006. Disponível em: <http://www.pucsp.br/ecurriculum>. Acesso em: 6 mar. 2007.

FREITAS, A. F. Ensino em Time por Professoras-Formadoras (Inglês): um ritmo constante de fragmentações, fluidez e contradiçōes. Tese (Doutorado em Letras) - Faculdade de Ciências e Letras, Universidade Estadual de São Paulo (UNESP), Assis, 2004.

GONÇALVES, J. R.. Pressupostos teóricos e metodológicos presentes na prática do docente formador de professores de inglês. Tese (Doutorado em Letras) Universidade Estadual Paulista (UNESP), Assis, 2006.

HALU, R. C. Formação de formadoras de professoras de inglês em contexto de formação continuada (NAP-UFPR). 246 f. Tese (Doutorado em Letras) - Setor de Ciências Humanas, Letras e Artes, Universidade Federal do Paraná (UFPR), Curitiba, 2010.

MASSETO, M. T. Competência Pedagógica do Professor Universitário. São Paulo: Summus Editorial, 2003. 
MESSINA, G. Investigación acerca de la formación docente: un estado del arte en los noventa. Revista Iberoamericana de Educación, n. 19, p. 145-207, 1999. MIZUKAMI, M. G. N. Aprendizagem da docência: professores formadores. ECurriculum, São Paulo, v. 1, n. 1, p. 1-17, 2005. Disponível em: $<$ www.pucsp.br/ecurriculum/artigos_v_1 ${ }_{-}{ }_{-}{ }_{1}{ }_{-} \mathrm{dez}_{-} 2005 /$ mizukamiartigo.pdf>. Acesso em: 20 out. 2006.

OLIVEIRA, A. T. C. C. Saberes e Práticas de Formadores de Professores que Vão Ensinar Matemática nos Anos Iniciais. 228 f. Tese (Doutorado em Educação) Pontifícia Universidade Católica do Rio de Janeiro, Rio de Janeiro, 2007.

ORTALE, F. L. Quando o Foco é a Formadora... conflitos na interação com uma professora de língua estrangeira. $214 \mathrm{f}$. Tese (Doutorado em Linguística Aplicada) - Instituto de Estudos da Linguagem, Universidade Estadual de Campinas (UNICAMP), Campinas, 2003.

ORTENZI, D. I. B. G. A Produção Coletiva de um Material Pedagógico para a Prática de Ensino de Inglês. 282 f. Tese (Doutorado em Estudos da Linguagem) - Centro de Letras e Ciências Humanas, Universidade Estadual de Londrina, Londrina, 2007.

ORTENZI, D. I. B. G.; GIMENEZ, T.; CRISTOVAO, V. TORRES, A. C. G.; FURTOSO, V. B. Formadoras de professores de língua inglesa: aprendizagem e participação. In: VII Congresso Brasileiro de Linguística Aplicada, 2005, São Paulo. Anais do VII CBLA. São Paulo: ALAB, p. 1-16, 2005.

PERIN, J. O. R. Políticas educacionais e formação de professores de língua estrangeira: algumas considerações de uma formadora de professores em formação. Revista Teoria e Prática da Educação, Maringá: UEM, v. 9. n. 1, p. 9197, jan./abr. 2006.

PERIN, J. Emergência e Construção de uma Comunidade de Prática de Formadores de Professores de Lingua Inglesa. $264 \mathrm{f}$. Tese (Doutorado em Estudos da Linguagem) - Universidade Estadual de Londrina, Londrina, 2009.

QUADROS, A. L. Aulas de Ensino Superior: uma visão sobre professores de disciplinas científicas na licenciatura em Química da UFMG. 293 f. Tese (Doutorado). Faculdade de Educação, Universidade Federal de Minas Gerais, Belo Horizonte, 2010.

RAMOS, S. M.; CAMARGO, G. P. Q. P. A formação de professores durante a Prática de Ensino nos cursos de Letras: foco no trabalho dos formadores, suas opções metodológicas e abordagens. In: GIMENEZ, T. (Org.). Tecendo as Manhãs: pesquisa participativa e formação de professores de inglês. Londrina: UEL, 2007. p. 41-62. 
RODRIGUES, M. I. R. Aspectos do Desenvolvimento Profissional dos Formadores de Professores de Ciências no Contexto de Integração - Universidade, Diretorias Regionais de Ensino e Escolas. Tese (Doutorado em Educação) - Faculdade de Educação, Universidade de São Paulo, São Paulo, 2006.

ROSEMBERG, D. S. A Formação Continuada de Professores Universitários: do instituído ao instituinte. Dissertação (Mestrado). 210 p. Faculdade de Educação, Universidade Federal do Espírito Santo, Vitória, 1999.

VAILLANT, D. Formação de Formadores: estado da prática. Rio de Janeiro: PREAL (Programa de Promoção da Reforma Educativa na América Latina e Caribe), 2003. 